\title{
Morfogênese e produção de biomassa do capim-tanzânia adubado com nitrogênio e cálcio ${ }^{1}$
}

\author{
Cristiane Prezotto Silveira², Francisco Antonio Monteiro ${ }^{3}$
}

\begin{abstract}
1 Parte da tese de Mestrado da primeira autora apresentada à Escola Superior de Agricultura "Luiz de Queiroz" - USP para obtenção do título de Mestre em Agronomia, na área de concentração: Solos e Nutrição de Plantas. Projeto apoiado pelo CNPq.

2 Pós-graduanda em Solos e Nutrição de Plantas, Caixa Postal 9, CEP: 13418-900, Piracicaba-SP. Bolsista da CAPES.

3 Departamento de Ciência do Solo, Caixa Postal 9, CEP: 13418-900, Piracicaba-SP. Bolsista do CNPq.
\end{abstract}

RESUMO - Neste estudo avaliou-se a influência da adubação com doses combinadas de nitrogênio e cálcio na emissão de folhas e perfilhos, a área foliar e a produção de massa seca da parte aérea do capim-tanzânia. O capim-tanzânia foi cultivado em solução nutritiva, utilizando-se sílica como substrato, em experimento em casa de vegetação. O experimento foi conduzido em delineamento estatístico de blocos ao acaso, com quatro repetições, utilizando-se um esquema fatorial $5^{2}$ fracionado, com combinações de cinco doses de nitrogênio $\left(2 ; 9 ; 16 ; 23\right.$ e $\left.30 \mathrm{mmol} \mathrm{L}^{-1}\right)$ e cinco doses de cálcio $(0,50 ; 1,75 ; 3,00$ 4,25 e $5,50 \mathrm{mmol} \mathrm{L}^{-1}$ ). Foram realizados três cortes nas plantas, o primeiro aos 39 dias após o transplantio, o segundo aos 30 dias após o primeiro corte e o terceiro aos 28 dias após o segundo corte. As doses de cálcio não interagiram com as de nitrogênio para as variáveis testadas no primeiro corte do capim-tanzânia. O número de perfilhos e de folhas dependeu apenas do suprimento de nitrogênio. A combinação entre doses de nitrogênio e de cálcio foi determinante para a área foliar no terceiro corte e para a produção de massa seca da parte aérea no segundo e terceiro cortes do capim-tanzânia. As máximas respostas produtivas da gramínea ocorreram com suprimento mínimo de nitrogênio de $23 \mathrm{mmol} \mathrm{L}^{-1}$. A utilização de cálcio em dose não inferior a $2 \mathrm{mmol} \mathrm{L}^{-1} \mathrm{na}$ solução nutritiva não restringiu as respostas produtivas desse capim, mesmo na presença de elevadas doses de nitrogênio.

Palavras-chave: área foliar, folhas, massa seca, Panicum maximum, perfilhos

\section{Nitrogen and calcium fertilization on tanzaniagrass morphogenesis and yield}

\begin{abstract}
The objective of this study was to evaluate grass responses to combined rates of nitrogen and calcium. Measured response variables included leaf number, tiller number, leaf area, and DM yield. Tanzaniagrass was grown in nutrient solution with ground quartz as substrate, in a greenhouse experiment. The experiment was carried out in randomized block design, with four replications. A fractionated $5^{2}$ factorial was used, with combinations of five nitrogen rates $(2,9,16,23$, and $\left.30 \mathrm{mmol} \mathrm{L}^{-1}\right)$ and five calcium rates $\left(0.50,1.75,3.00,4.25\right.$, and $\left.5.50 \mathrm{mmol} \mathrm{L}^{-1}\right)$. Three harvests were performed, the first one 39 days after seedlings transplanting, the second one 30 days after the first harvest, and the third one 28 days after the second harvest. Calcium rates did not interact with the nitrogen rates for the productive variables in the first growth of this grass. The number of tillers and leaves depended only on nitrogen rates. Combination of nitrogen and calcium rates was necessary for tanzaniagrass leaf area at the third growth, and for the shoot biomass at the second and third growths. Maximum productive responses of this forage were reached with the minimum supply of nitrogen of $23 \mathrm{mmol} \mathrm{L}^{-1}$. The use of calcium at rate not inferior to $2 \mathrm{mmol} \mathrm{L}^{-1}$ did not reduce productive variables of this grass, even with the supply of high nitrogen rate.
\end{abstract}

Key Words: dry mass, leaf area, leaves, Panicum maximum, tillers

\section{Introdução}

O modelo extrativista de exploração de pastagens, comum no Brasil, não garante altas produtividades, qualidade e persistência de espécies de elevada exigência em fertilidade do solo, como o Panicum maximum Jacq. (Werner et al., 1996).

O capim-tanzânia (Panicum maximum) tem mostrado maior eficiência na produção de massa seca total e foliar, maior ganho de peso diário por animal e maior taxa de lotação das pastagens quando comparado ao capimcolonião (Panicum maximum). Assim, tem merecido grande aceitação pelos agropecuaristas brasileiros na implantação de novas pastagens (Jank, 1994).

O aumento da produção de forragem depende da adequada disponibilidade de nutrientes, especialmente do nitrogênio. A necessidade desse nutriente é maior após o desenvolvimento inicial da gramínea, quando passa a contribuir expressivamente para a produção de massa seca e a concentração de nitrogênio (Monteiro \& Werner, 1977). 
O nitrogênio é importante para a produtividade de gramíneas forrageiras, pois é responsável por características como o tamanho das folhas e dos colmos e o aparecimento e desenvolvimento dos perfilhos, fatores diretamente relacionados à produção de massa seca da planta forrageira (Werner, 1986).

As informações sobre a produção de massa seca de gramíneas forrageiras relacionada ao cálcio são escassas. Estudos como os de Werner et al. (1979) e Mitidieri (1995) têm mostrado que a calagem nem sempre favorece a produtividade dessas plantas. Respostas à calagem são mais freqüentes na implantação e menos comuns na manutenção das pastagens. Calagem acima do necessário, além de não refletir em aumento de produção de massa do capim, pode induzir a menor disponibilidade de micronutrientes para as plantas (Macedo, 2004).

Em estudo sobre a correção de solo e a adubação em pastagens de capim-elefante (Pennisetum purpureum), Corsi \& Nussio (1993) relataram que a adubação nitrogenada deve ser realizada quando há equilíbrio entre os nutrientes presentes em níveis elevados no solo. Quanto aos cátions trocáveis, em termos gerais, esses autores afirmaram ser desejável que o cálcio componha de 65 a $85 \%$ da capacidade de troca de cátions do solo. Entretanto, há nítida falta de resultados experimentais quanto ao aspecto da nutrição em cálcio de gramíneas forrageiras quando é realizada adubação nitrogenada.

A hipótese para este estudo é que o capim-tanzânia pode ter maior ou menor dependência do cálcio quando há variação na disponibilidade de nitrogênio no substrato. Objetivou-se avaliar as informações relativas às alterações na emissão de folhas e perfilhos, na área foliar e na produção de massa seca da parte aérea do capim-tanzânia adubado com combinações por nitrogênio e cálcio.

\section{Material e Métodos}

O experimento foi realizado em casa de vegetação em Piracicaba, SP, no período de setembro a dezembro de 2004 e a espécie forrageira utilizada foi o capim-tanzânia. O capim foi submetido às combinações de cinco doses de nitrogênio $\left(2,9,16,23\right.$ e $\left.30 \mathrm{mmol} \mathrm{L}^{-1}\right)$ com cinco doses de cálcio $\left(0,50 ; 1,75 ; 3,00 ; 4,25\right.$ e $\left.5,50 \mathrm{mmol} \mathrm{L}^{-1}\right)$. As soluções nutritivas foram preparadas a partir da solução completa de Sarruge (1975), modificada para atender às doses de nitrogênio e cálcio.

Empregou-se um estudo de superfície de resposta baseado em desenho experimental composto central modificado de um fatorial $5^{2}$ fracionado, de acordo com Littell \& Mott (1975). Segundo esse esquema, obtiveram-se
13 combinações entre as doses de nitrogênio e de cálcio, em mmol L-1: 2-0,5; 2-3,0; 2-5,5; 9-1,75; 9-4,25; 16-0,5; 16-3,0; $16-5,5 ; 23-1,75 ; 23-4,25 ; 30-0,5 ; 30-3,0$ e $30-5,5$. Odelineamento experimental foi de blocos ao acaso, com quatro repetições.

Considerando os resultados obtidos com capins tropicais por Abreu (1994) e Santos (2003), que utilizaram conjuntamente $\mathrm{N}_{-} \mathrm{NO}_{3}{ }^{-}$e N-NH${ }_{4}{ }^{+}$na solução e encontraram maior produção das plantas, foi empregada a proporção de 65\%:35\% de $\mathrm{N}^{-\mathrm{NO}_{3}}{ }^{-}: \mathrm{N}^{-\mathrm{NH}_{4}}{ }^{+}$na solução nutritiva. A concentração de potássio na solução nutritiva proposta por Sarruge (1975) é de 6,0 $\mathrm{mmol} \mathrm{L}^{-1}$ e foi alterada nesse estudo para $8,0 \mathrm{mmol} \mathrm{L}^{-1}$, em razão dos resultados relatados por Ferragine \& Monteiro (1999) e Mattos et al. (2002).

A semeadura foi realizada no dia 09 de setembro de 2004 em bandejas plásticas contendo areia lavada em água corrente e em água desionizada. Catorze dias após a semeadura, realizou-se o transplantio de 15 mudas de aproximadamente $3 \mathrm{~cm}$ em cada vaso plástico com capacidade de 3,6 litros, contendo sílica moída como substrato, também lavada em água corrente e em água desionizada.

Após o transplantio das mudas, foi colocado em cada vaso um litro de solução nutritiva diluída a $25 \%$ da concentração proposta para cada tratamento, que foi empregada por três dias até a troca para as soluções definitivas. Desbastes periódicos das mudas foram realizados até permanecerem cinco plantas por vaso. As soluções nutritivas foram renovadas a cada 14 dias, circuladas quatro vezes ao dia para a aeração das raízes, drenadas no fim do dia e fornecidas pela manhã, quando se completou o volume de um litro com água desionizada.

As plantas foram submetidas a três cortes: o primeiro aos 39 dias após o transplantio, o segundo aos 30 dias após o primeiro corte e o terceiro aos 28 dias após o segundo corte. Imediatamente após a colheita das lâminas foliares, determinou-se a área foliar em cada unidade experimental com o uso do integrador de área foliar LICOR ${ }^{\circledR}$ LI-3000.

Nos três períodos de desenvolvimento das plantas, as lâminas de folhas expandidas (com lígula visível) e os perfilhos foram contados para obtenção do número total de folhas e de perfilhos em cada vaso.

Todo o material vegetal colhido nos três períodos de crescimento foi seco em estufa com circulação forçada a $65^{\circ} \mathrm{C}$ até massa seca constante e foi pesado em balança de precisão. A produção de massa seca da parte aérea foi determinada em cada um dos cortes da gramínea.

Os resultados foram submetidos a análises estatísticas utilizando-se o aplicativo "Statistical Analysis System" (SAS , 2000). Utilizou-se inicialmente o teste $\mathrm{Fe}$, para casos de significância $(\mathrm{P}<0,05)$ da interação de doses de nitrogênio $\times$ doses de cálcio, efetuaram-se análises de regressão 
polinomial (superfície de resposta) pelo procedimento RSREG. Nos casos de interação não-significativa $(\mathrm{P}>0,05)$, utilizou-se o procedimento GLM para os estudos de regressão envolvendo especificamente a dose do nutriente para o qual o efeito foi significativo $(P<0,05)$ no teste $\mathrm{F}$.

\section{Resultados e Discussão}

O número de folhas expandidas nos três cortes do capimtanzânia não foi influenciado pela interação doses de nitrogênio $\times$ doses de cálcio fornecidas na solução nutritiva. No entanto, em todos os cortes da gramínea, sofreu efeito significativo das doses de nitrogênio (Figura 1).

Pelas equações de segundo grau, constatou-se que as doses de nitrogênio de 24,34 e $26,93 \mathrm{mmol} \mathrm{L}^{-1}$ foram as causas do número máximo de folhas da gramínea no primeiro (Figura 1a) e segundo cortes (Figura 1b), respectivamente. No terceiro corte, a dose de nitrogênio que ocasionou a maximização do número de folhas excedeu a maior dose estudada neste trabalho (Figura 1c).

Lavres Jr. et al. (2004) verificaram que as doses de nitrogênio interferiram positivamente no número de folhas expandidas em dois cortes do capim-aruana Panicum maximum), ajustando-se a modelo quadrático de regressão, e que as doses de nitrogênio que resultaram em número máximo de folhas expandidas foram 24,57 e 23,93 $\mathrm{mmol} \mathrm{L}^{-1}$, respectivamente, para o primeiro e segundo cortes dessa gramínea forrageira. Em capim-marandu (Brachiaria brizantha) adubado com nitrogênio e enxofre, Batista \& Monteiro (2006) detectaram que as doses de nitrogênio de $25,60 \mathrm{mmol} \mathrm{L}^{-1}$ no primeiro corte e de $27,07 \mathrm{mmol} \mathrm{L}^{-1}$ no segundo corte promoveram a maximização do número de folhas expandidas. Bonfim-da-Silva \& Monteiro (2006) constataram que a adubação com nitrogênio afetou o número de folhas expandidas do capim-braquiária Brachiaria decumbens) em três cortes, obtendo-se ajuste a modelo quadrático de regressão, que resultou nas máximas produções de folhas nas doses de 256,300 e $285 \mathrm{mg} \mathrm{dm}^{-3}$ no primeiro, segundo e terceiro cortes, respectivamente.

As doses de nitrogênio que ocasionaram maximização do número de folhas mantiveram-se entre 24 e $27 \mathrm{mmol} \mathrm{L}^{-1}$, corroborando a afirmação de Lemaire \& Chapman (1996) de que a adubação nitrogenada tem efeito significativo na taxa de aparecimento de folhas.

O número de folhas atingiu máximos de 150 a 220 folhas por vaso (Figura 1), neste experimento desenvolvido com cinco plantas por vaso. Desse modo, o perfilhamento do capimtanzânia atingiu valores máximos de 5, 9 e 12 perfilhos por planta, correspondentes a 24,45 e 60 perfilhos por vaso (Figura 2), respectivamente, no primeiro, segundo e terceiro cortes.
Não houve significância para a interação doses de nitrogênio $\times$ doses de cálcio, mas foi observado efeito significativo do suprimento de nitrogênio no número de
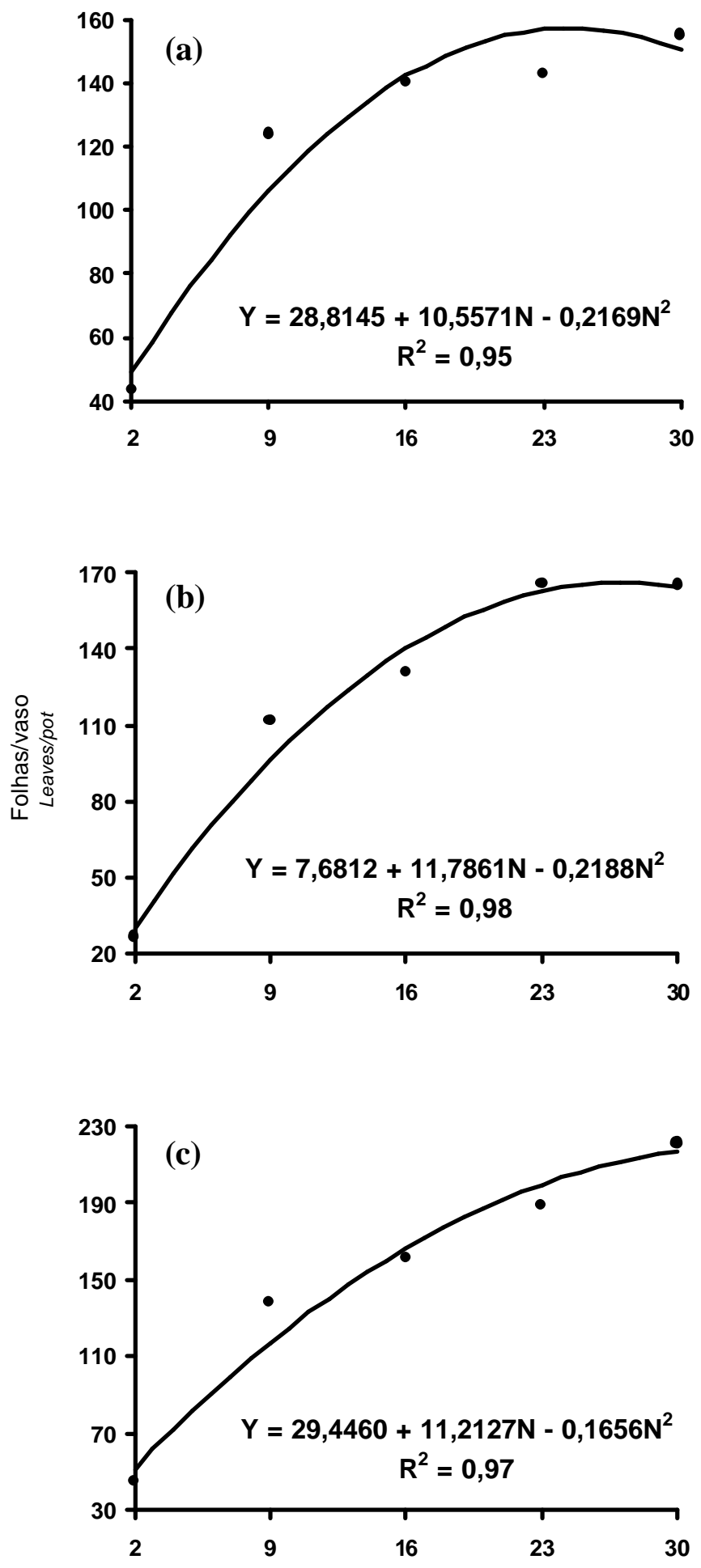

$\mathrm{N}(\mathrm{mmol} \mathrm{L-1})$

Figura 1 - Folhas expandidas por vaso no primeiro (a), segundo (b) e terceiro (c) cortes do capim-tanzânia adubado com nitrogênio.

Figure 1 - Expanded leaves per pot at the first (a), second (b) and third (c) harvests of tanzaniagrass as related to the nitrogen rates. 
perfilhos do capim-tanzânia em todos os cortes. O perfilhamento foi representado por equação do segundo grau em relação às doses de nitrogênio para cada um dos três períodos de crescimento.

A dose de nitrogênio necessária para o máximo perfilhamento no primeiro corte foi de $22,69 \mathrm{mmol} \mathrm{L}^{-1}$ (Figura 2a). No segundo corte, o número máximo de perfilhos foi obtido com a dose de nitrogênio de $24,55 \mathrm{mmol} \mathrm{L}^{-1}$ (Figura $2 b$ ). $\mathrm{O}$ número de perfilhos variou com as doses de nitrogênio também no terceiro corte e, de acordo com a equação de segundo grau, a dose de nitrogênio que corresponderia ao perfilhamento máximo do capim-tanzânia excedeu as doses de nitrogênio avaliadas neste experimento (Figura 2c).

Efeitos positivos e representados por modelos quadráticos das doses de nitrogênio no perfilhamento do capim-mombaça (Panicum maximum) foram verificados por Lavres Jr. \& Monteiro (2003), que avaliaram o suprimento conjunto de doses de nitrogênio e potássio na solução nutritiva e constataram que as doses de nitrogênio de 21,14 e $24,43 \mathrm{mmol} \mathrm{L}^{-1}$ corresponderam ao máximo perfilhamento no primeiro e segundo cortes.

Trabalhando com capim-aruana adubado com doses de nitrogênio, Colozza et al. (2000) verificaram que o número de perfilhos variou significativamente com as doses de nitrogênio e que o número máximo de perfilhos ocorreu nas doses de nitrogênio de $150 \mathrm{mg} \mathrm{kg}^{-1}$ para o primeiro e de $233 \mathrm{mg} \mathrm{kg}^{-1}$ para o segundo corte do capim-aruana.

Lavres Jr. et al. (2004), comparando o ponto de máximo perfilhamento do capim-aruana em dois cortes, verificaram que as doses de nitrogênio de 26,64 e $21,36 \mathrm{mmol} \mathrm{L}^{-1}$ corresponderam ao máximo número de perfilhos no primeiro e segundo cortes, respectivamente.

Para o perfilhamento do capim-tanzânia (Figura 2), as doses de nitrogênio que proporcionaram o máximo perfilhamento foram de $22 \mathrm{e} 25 \mathrm{mmol} \mathrm{L}^{-1}$, bem mais elevadas que a usual da solução de Sarruge (1975), de $15 \mathrm{mmol} \mathrm{L}^{-1}$. Lemaire \& Chapmam (1996) evidenciaram que o nitrogênio e outros fatores ambientais podem influenciar as características morfogênicas (taxas de aparecimento de folhas e de alongamento e de senescência foliar) e estruturais (densidade de perfilhos e tamanho das folhas) do capim, o que foi comprovado neste trabalho.

A área foliar do capim-tanzânia diferiu entre os dois primeiros cortes e o terceiro corte. A interação doses de nitrogênio $\times$ doses de cálcio não foi significativa para a área das lâminas foliares coletadas no primeiro e segundo cortes, mas foi significativa para o terceiro corte.

No primeiro e segundo cortes, foi observado efeito significativo das doses de nitrogênio na área foliar, com ajuste dos resultados ao modelo quadrático de regressão.
A área foliar máxima no primeiro e segundo cortes foi obtida com as doses de nitrogênio de 23,87 (Figura 3a) e 28,31 $\mathrm{mmol} \mathrm{L}^{-1}$ (Figura 3b).
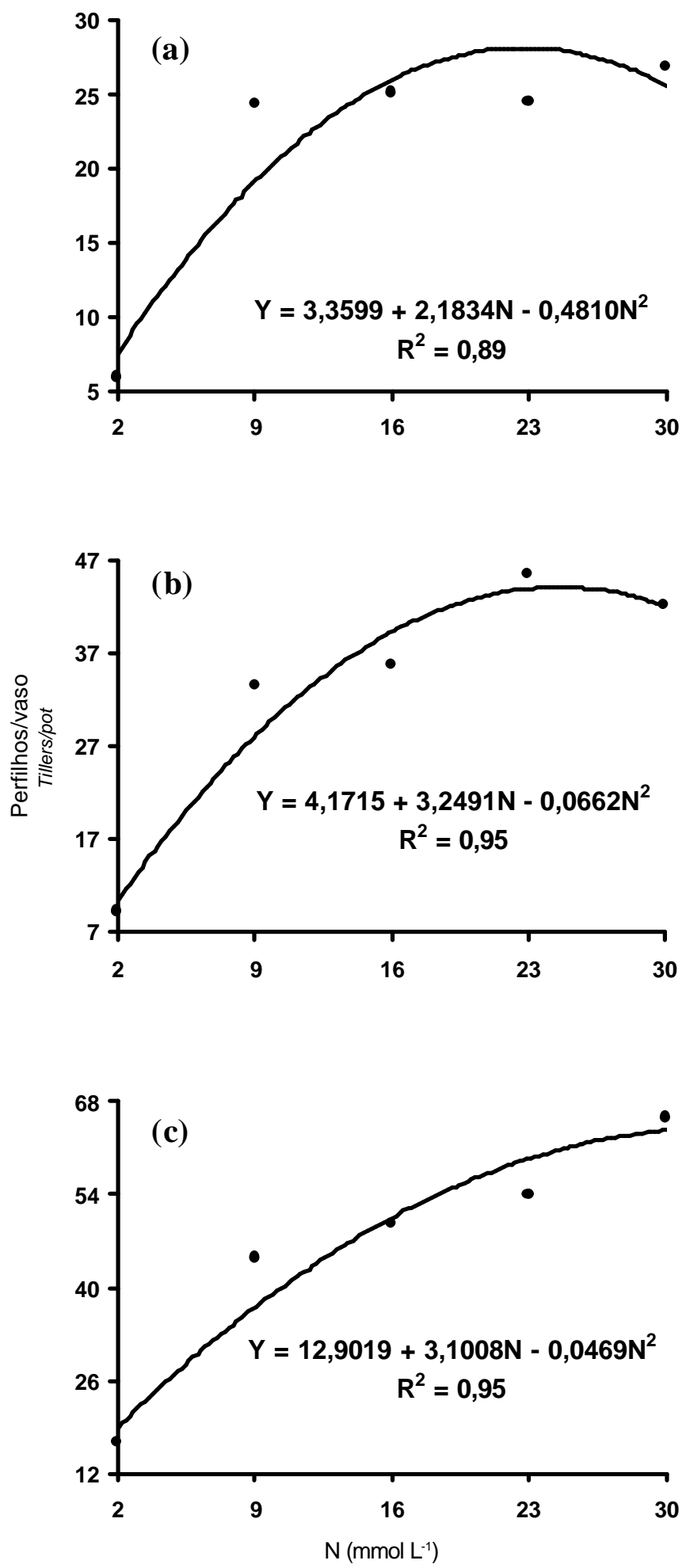

Figura 2 - Número de perfilhos por vaso no primeiro (a), segundo (b) e terceiro (c) cortes do capim-tanzânia adubado com nitrogênio.

Figure 2 - Number of tillers per pot at the first (a), second (b) and third (c) harvests of tanzaniagrass as related to the nitrogen rates. 
Lavres Jr. \& Monteiro (2003) avaliaram os efeitos de combinações de doses de nitrogênio e de potássio na área foliar do capim-mombaça e verificaram que o intervalo das doses de nitrogênio de 24 a $33 \mathrm{mmol} \mathrm{L}^{-1}$ foi a causa da máxima área foliar nos dois cortes da gramínea.

Em experimento realizado com o objetivo de avaliar doses de nitrogênio e idades de crescimento no capimmarandu, Santos Jr. \& Monteiro (2003) constataram que as doses de nitrogênio necessárias para a maximização da área foliar variaram de 19,36 a $21,14 \mathrm{mmol} \mathrm{L}^{-1}$.

$\mathrm{O}$ incremento no fornecimento de nitrogênio também promoveu aumento na área foliar do capim-aruana, observando-se que as áreas foliares máximas no primeiro e segundo cortes foram promovidas pelas doses de nitrogênio de 28,57 e 24,14 $\mathrm{mmol} \mathrm{L}^{-1}$, respectivamente (Lavres Jr. et al., 2004).

A área foliar do capim-tanzânia (Figura 3 ) foi fortemente influenciada pelas doses de nitrogênio, sendo maximizada em doses de 24 a $28 \mathrm{mmol} \mathrm{L}^{-1}$. De acordo com Lemaire \&

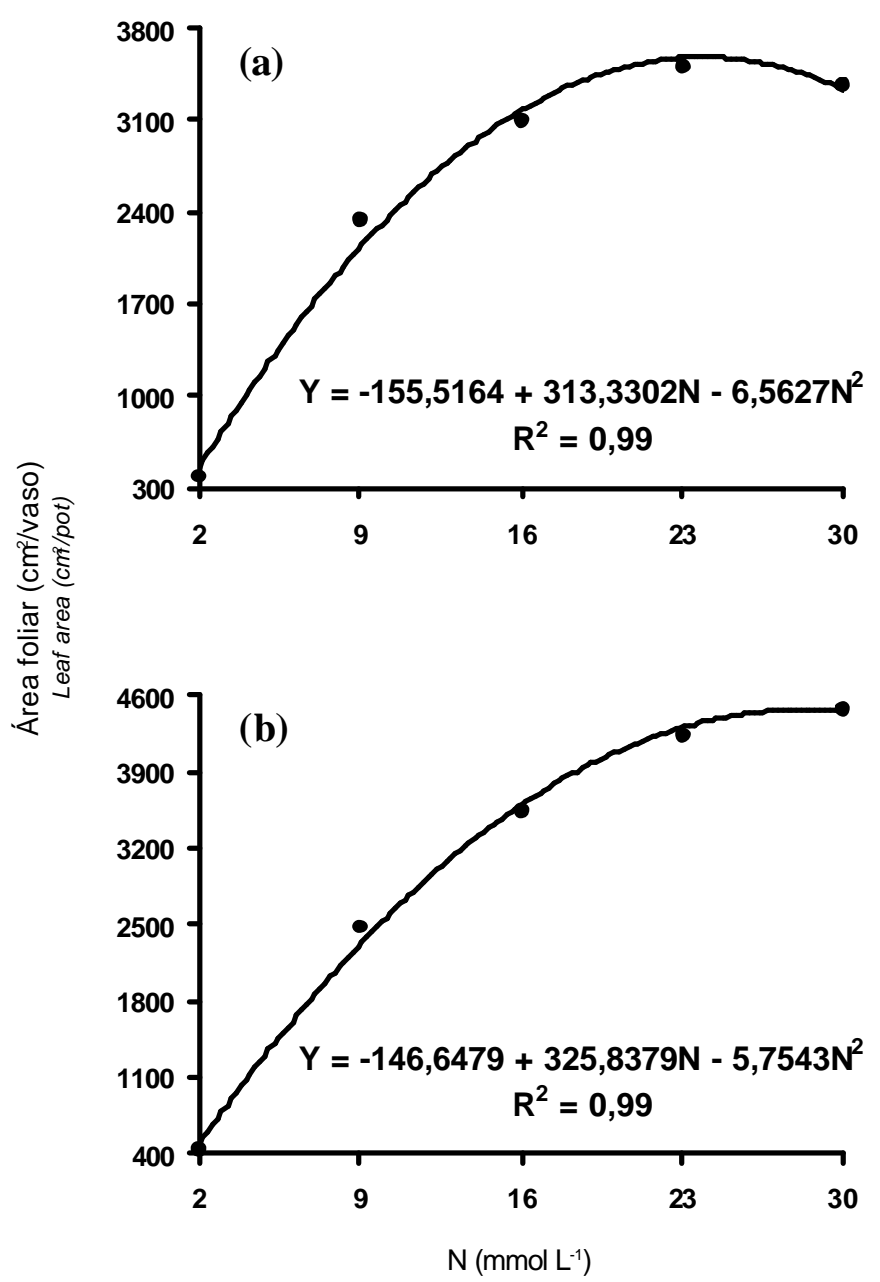

Figura 3 - Área foliar por vaso no primeiro e segundo cortes do capim-tanzânia adubado com nitrogênio.

Figure 3 - Leaf area per pot at the first (a) and second (b) harvests of tanzaniagrass as related to the nitrogen rates.
Chapmam (1996), o nitrogênio proporciona elongação foliar - a folha fica mais extensa com maior fornecimento desse nutriente e, conseqüentemente, a área foliar é incrementada. A área foliar é determinante do índice de área foliar, um atributo muito importante para a pastagem.

A interação doses de nitrogênio $\times$ doses cálcio foi significativa para a área das folhas coletadas no terceiro corte do capim-tanzânia, com ajuste dos resultados a modelo polinomial de regressão. O nitrogênio resultou nos maiores impactos na área foliar do capim-tanzânia, mas, quando fornecidas altas doses de nitrogênio, foi necessária sua combinação com o cálcio para maximização da área foliar ao terceiro corte. A área foliar máxima foi obtida com as mais altas doses de nitrogênio (23 a $30 \mathrm{mmol} \mathrm{L}^{-1}$ ) associadas à uma dose mínima de cálcio, em torno de $1,75 \mathrm{mmol} \mathrm{L}^{-1}$ na solução nutritiva (Figura 4).

Rodrigues (2002) observou significância da interação de doses de nitrogênio $\times$ doses de calcário na área foliar do capim-braquiária. Também, no estudo das doses de nitrogênio dentro de cada dose de calcário, verificou incremento nessa variável em todas as doses de calcário, no primeiro e segundo cortes, enquanto, no estudo das doses de calcário dentro de cada dose de nitrogênio, constatou efeito significativo para as doses de nitrogênio de 630 e de $1.080 \mathrm{mg} \mathrm{kg}^{-1}$ de solo no primeiro corte e apenas para a dose $1.080 \mathrm{mg} \mathrm{kg}^{-1}$ de solo, no segundo corte.

Apenas as doses de nitrogênio foram determinantes da área foliar nos dois primeiros cortes. Somente no terceiro corte, as doses de cálcio passaram a ter relevância na asso-

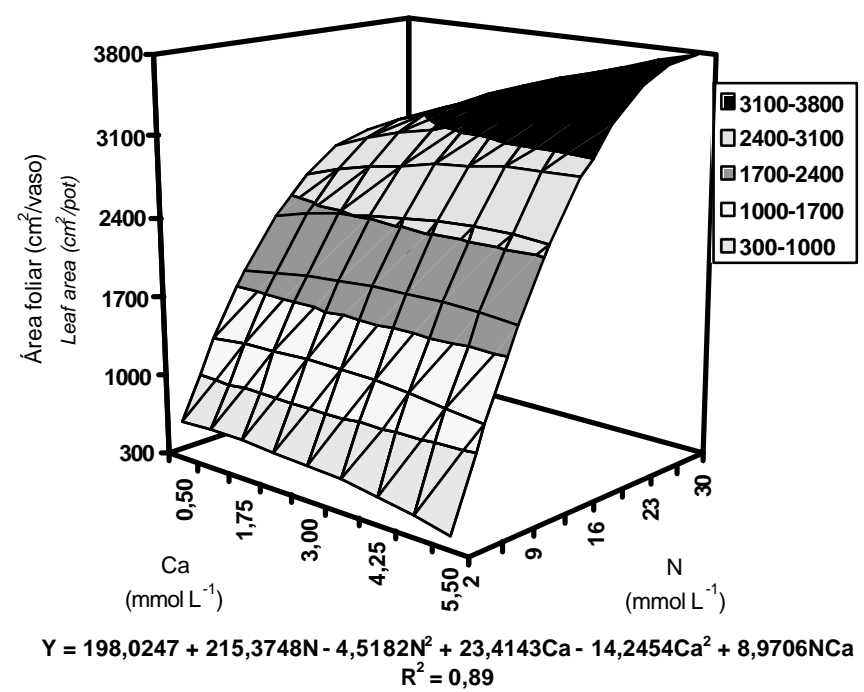

Figura 4 - Área foliar por vaso no terceiro corte do capimtanzânia adubado com nitrogênio e cálcio.

Figure 4 - Leaf area per pot at the third harvest of tanzaniagrass as related to the combinations of the nitrogen and calcium rates. 
ciação com as doses de nitrogênio, não sendo necessário o fornecimento de cálcio na dose de $5 \mathrm{mmol} \mathrm{L}^{-1}$ (a concentração da solução de Sarruge, como usada para a maioria das culturas) para maximizar a área foliar dessa gramínea.

A produção de massa seca da parte aérea no primeiro corte não apresentou significância para a interação doses de nitrogênio $\times$ doses de cálcio. Entretanto, essa interação foi significativa para a produção no segundo e terceiro cortes.

No primeiro corte do capim-tanzânia, os resultados ajustaram-se a modelo quadrático de regressão e a dose de nitrogênio de $25,46 \mathrm{mmol} \mathrm{L}^{-1}$ proporcionou a máxima produção de massa seca da parte aérea (Figura 5).

Doses de nitrogênio mais elevadas $\left(31,93 \mathrm{mmol} \mathrm{L}^{-1}\right)$ que as obtidas neste estudo para obtenção da máxima produção de massa seca da parte aérea foram encontradas por Manarin \& Monteiro (2002), para o capim-mombaça no primeiro corte. Contudo, Lavres Jr. \& Monteiro (2002) verificaram que a dose de nitrogênio de $27,60 \mathrm{mmol} \mathrm{L}^{-1}$ proporcionou o valor máximo de produção de massa seca no primeiro corte do capim-mombaça quando associada à dose de potássio de 11,13 $\mathrm{mmol} \mathrm{L}^{-1}$.

Colozza et al. (2000) avaliaram as respostas do capimaruana a doses de nitrogênio e verificaram que a produção de massa seca da parte aérea variou positivamente em resposta às doses de nitrogênio. As produções máximas foram obtidas nas doses de nitrogênio de 171 e de $332 \mathrm{mg} \mathrm{kg}^{-1}$ no primeiro e segundo cortes da gramínea.

Trabalhando com o capim-aruana, Lavres Jr. et al. (2004) observaram que a dose de nitrogênio de $24 \mathrm{mmol} \mathrm{L}^{-1}$ foi responsável pela máxima produção de massa seca da parte aérea no primeiro corte.

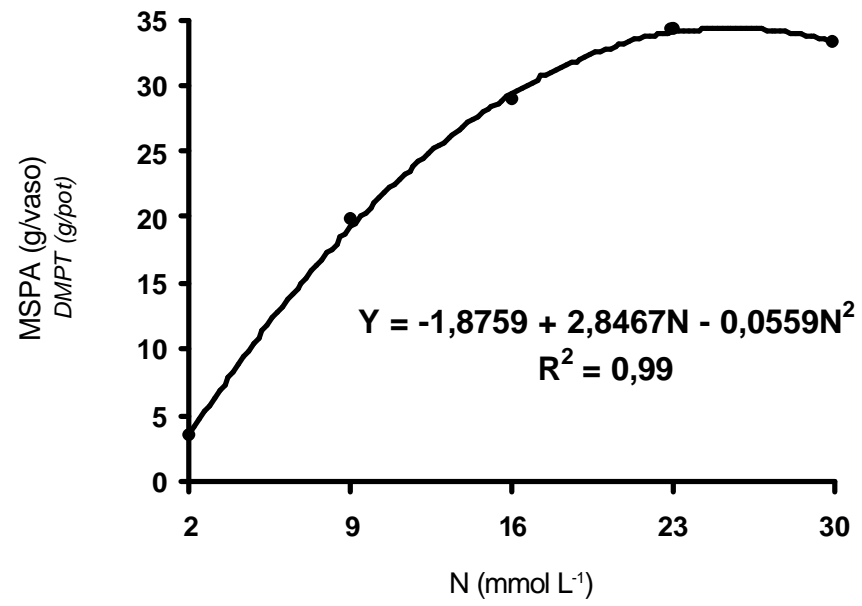

Figura 5 - Produção de massa seca da parte aérea por vaso (MSPA) no primeiro corte do capim-tanzânia adubado com nitrogênio.

Figure 5 - Shoot DM yield per pot (DMPT) at the first harvest of tanzaniagrass as related to the nitrogen rates.
Santos Jr. \& Monteiro (2003), avaliando doses de nitrogênio e idades de crescimento no capim-marandu, constataram que doses de nitrogênio de 18,36 a $21,71 \mathrm{mmol} \mathrm{L}^{-1}$ maximizaram a produção de massa seca da parte aérea.

Para o capim-braquiária submetido a doses de nitrogênio e de potássio, Ferragine \& Monteiro (1999) relataram que, no primeiro corte da gramínea, a dose de nitrogênio de 31 mmol L $\mathrm{L}^{-1}$, associada à dose de potássio de $6 \mathrm{mmol} \mathrm{L}^{-1}$, resultou na maior produção de massa seca da parte aérea.

No segundo e terceiro cortes, a análise da superfície de resposta demonstrou que as doses de nitrogênio foram altamente determinantes na produtividade do capimtanzânia. Nas mais altas doses de nitrogênio (23 a $30 \mathrm{mmol} \mathrm{L}^{-1}$ ) fornecidas na solução nutritiva, somente as doses mais baixas de cálcio $\left(0,5\right.$ a $\left.1,75 \mathrm{mmol} \mathrm{L}^{-1}\right)$ mostraram-se limitantes à maximização da produção da parte aérea da gramínea forrageira (Figura 6).

Avaliando a fertilidade do solo no acúmulo de forragem e nutrição do capim-tanzânia sob pastejo na região dos Cerrados, Santos Jr. (2005) evidenciou que o nitrogênio e o cálcio estiveram relacionados ao expressivo aumento da produção de massa seca da gramínea forrageira.

Lavres Jr. \& Monteiro (2002) verificaram que a dose de nitrogênio de $29,43 \mathrm{mmol} \mathrm{L}^{-1}$ proporcionou a máxima produção de massa seca da parte aérea do capim-mombaça no segundo corte. Para o mesmo cultivar de capim, Manarin \& Monteiro (2002) constataram que a dose de nitrogênio de $30,93 \mathrm{mmol} \mathrm{L}^{-1}$ promoveu a maximização da produção de massa seca da parte aérea no segundo corte da gramínea forrageira.

Lavres Jr. et al. (2004), avaliando os componentes de produção e morfogênese do capim-aruana em resposta a doses de nitrogênio, verificaram que a dose de nitrogênio de $23,4 \mathrm{mmol} \mathrm{L}^{-1}$ correspondeu à máxima produção de massa seca da parte aérea do capim no segundo corte.

A produção de massa seca da parte aérea do capimtanzânia foi determinantemente influenciada pelas doses de nitrogênio, enquanto a demanda por cálcio foi pequena para a produtividade no segundo e terceiro cortes (Figura 6).

Segundo Lemaire \& Chapman (1996), as taxas de aparecimento foliar, elongação foliar e tempo de vida da folha são características geneticamente determinadas, mas podem ser influenciadas pela temperatura e disponibilidade de nitrogênio e de água. Neste experimento, as doses de nitrogênio elevaram a emissão das folhas e, conseqüentemente, as características estruturais das plantas, como tamanho das folhas e a densidade populacional de perfilhos, refletindo em aumentos na área foliar e na produtividade do capim-tanzânia.

Análise de correlação foi realizada para as variáveis morfogênicas estudadas em cada um dos três períodos de 

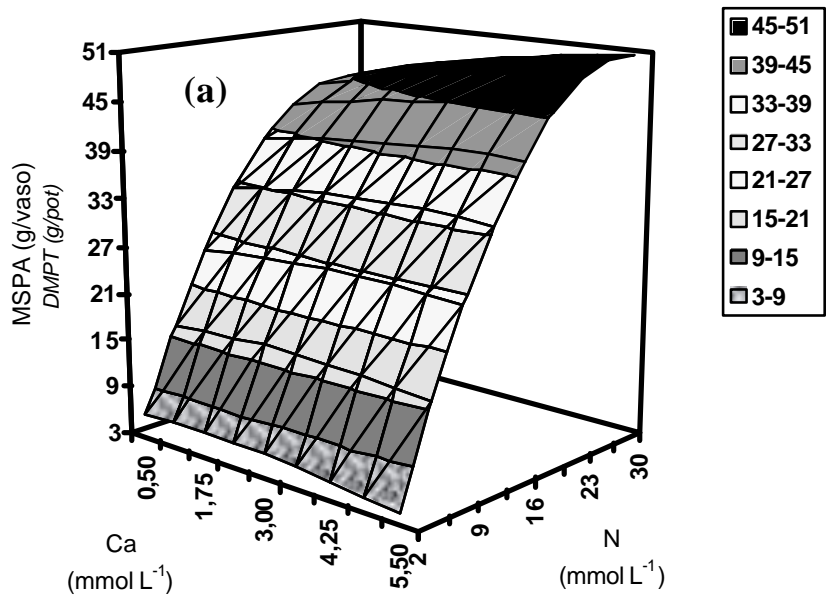

$Y=-1,2008+3,4720 N-0,0674 N^{2}+0,4508 C a-0,1433 \mathrm{Ca}^{2}+0,0619 \mathrm{NCa}$ $R^{2}=0,98$

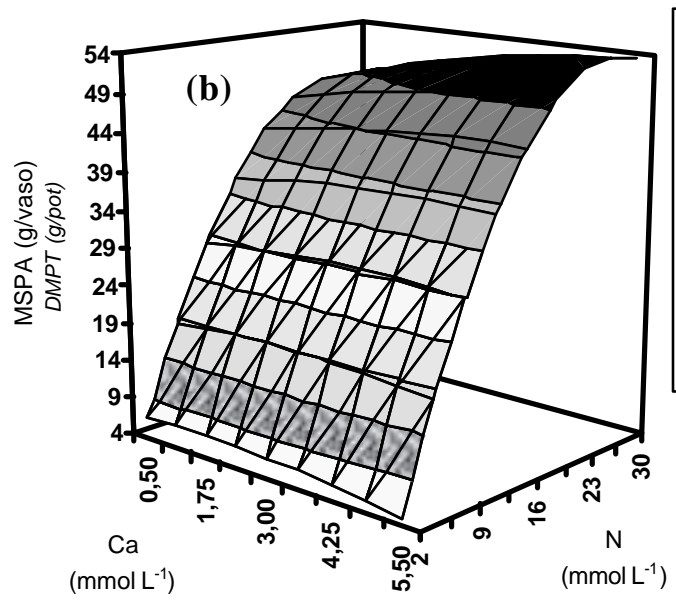

$Y=-1,1681+3,9295 \mathrm{~N}-0,0807 \mathrm{~N}^{2}+0,4370 \mathrm{Ca}-0,1526 \mathrm{Ca}^{2}+0,06904 \mathrm{NCa}$
$R^{2}=0,94$

Figura 6 - Produção de massa seca da parte aérea por vaso (MSPA) no segundo (a) e terceiro (b) cortes do capimtanzânia adubado nitrogênio e cálcio.

Figure 6 - Shoot DM yield per pot (DMPT) at the second (a) and third (b) harvests of tanzaniagrass as related to the combinations of nitrogen and calcium rates.

crescimento do capim-tanzânia, sendo observados elevados coeficientes de correlação entre essas variáveis nas épocas estudadas (Tabela 1). Em estudo sobre as correlações produção de massa seca da parte aérea $\times$ número de perfilhos, número de folhas $\times$ área foliar, Lavres Jr. et al. (2004) trabalharam com variáveis morfogênicas do capim-aruana adubado com doses de nitrogênio e encontraram correlação positiva entre essas variáveis-resposta em dois cortes da gramínea.
Tabela 1 - Coeficientes de correlação entre produção de massa seca da parte aérea (MSPA), folhas expandidas, número de perfilhos e área foliar de capim-tanzânia em três cortes

Table 1 - Correlation coefficients between shoot DM yield (DMPT), expanded leaves, number of tillers, and leaf area, at each harvest of tanzaniagrass

\begin{tabular}{lccc}
\hline $\begin{array}{l}\text { Corte } \\
\text { Harvest }\end{array}$ & $\begin{array}{c}\text { Primeiro } \\
\text { First }\end{array}$ & $\begin{array}{c}\text { Segundo } \\
\text { Second }\end{array}$ & $\begin{array}{c}\text { Terceiro } \\
\text { Third }\end{array}$ \\
\hline Variável (Variable) & \multicolumn{3}{c}{ MSPA (DMPT) } \\
\hline Folhas (Leaves) & $0,92^{* *}$ & $0,91 * *$ & $0,82 * *$ \\
Perfilhos (Tillers) & $0,90^{* *}$ & $0,87 * *$ & $0,82 * *$ \\
Área foliar (Leaf area) & $0,96 * *$ & $0,93^{* *}$ & $0,91 * *$ \\
\hline
\end{tabular}

Folhas (Leaves)

Perfilhos (Tillers) $\quad 0,97 * * \quad 0,98 * * \quad 0,98 * *$

Área foliar (Leaf area) $0,95 * * \quad 0,88 * * \quad 0,86 * *$

Perfilhos (Tillers)

Área foliar (Leaf area) $\quad 0,94 * * \quad 0,86 * * \quad 0,85 * *$

** Significativo a 0,01 (significant at 0.010).

\section{Conclusões}

As doses de cálcio não interagiram com as de nitrogênio para as variáveis testadas no primeiro corte do capimtanzânia. O número de perfilhos e de folhas foi influenciado apenas pelo suprimento de nitrogênio. A combinação de doses de nitrogênio e de cálcio foi determinante tanto para a área foliar no terceiro corte como para a produção de massa seca da parte aérea no segundo e terceiro cortes. O suprimento mínimo de nitrogênio de $23 \mathrm{mmol} \mathrm{L}^{-1}$ foi necessário para maximizar as respostas produtivas da gramínea. Não houve restrição nas respostas produtivas desse capim em doses de cálcio não inferiores a $2 \mathrm{mmol} \mathrm{L}^{-1}$ na solução nutritiva, mesmo em presença de elevado fornecimento de nitrogênio.

\section{Literatura Citada}

ABREU, J.B.R. Níveis de nitrogênio e proporções de nitrato e amônio afetando produção, atividade da redutase do nitrato e composição de três gramíneas forrageiras. Piracicaba: Escola Superior de Agricultura "Luiz de Queiroz", 1994. 109p. Dissertação (Mestrado em Solos e Nutrição de Plantas) - Escola Superior de Agricultura "Luiz de Queiroz", 1994.

BATISTA, K.; MONTEIRO, F.A. Respostas do capim-Marandu a combinações de doses de nitrogênio e enxofre. Revista Brasileira de Zootecnia, v.35, n.4, p.1281-1288, 2006.

BONFIM-DA-SILVA, E.M.; MONTEIRO, F.A. Nitrogênio e enxofre em características produtivas do capim-braquiária proveniente de área de pastagem em degradação. Revista Brasileira de Zootecnia, v.35, n.4, p.1289-1297, 2006.

COLOZZA, M.T.; KIEHL, J.C.; WERNER, J.C. et al. Respostas de Panicum maximum cultivar Aruana a doses de nitrogênio. Boletim de Indústria Animal, v.57, n.1, p.21-32, 2000. 
CORSI, M.; NUSSIO, L.G. Manejo do capim-elefante: correção e adubação do solo. In: PEIXOTO, A.M.; MOURA, J.C.; FARIA, V.P. (Eds.). Simpósio sobre manejo da pastagem. 10.ed. Piracicaba: Fundação de Estudos Agrários Luiz de Queiroz, 1993. p.87-115.

FERRAGINE, M.D.C.; MONTEIRO, F.A. Combinações de doses de nitrogênio e potássio na nutrição mineral do capim-Braquiária. Boletim de Indústria Animal, v.56, n.1, p.25-33, 1999

JANK, L. Potencial do gênero Panicum. In: SIMPÓSIO BRASILEIRO DE FORRAGEIRAS E PASTAGENS, 1994, Campinas. Anais... s.1.: Colégio Brasileiro de Nutrição Animal, 1994. p.25-31.

LAVRES JR., J.; FERRAGINE, M.D.C.; GERDES, L. et al. Yield components and morphogenesis of Aruana grass in response to nitrogen supply. Scientia Agricola, v.61, n.6, p.632-639, 2004.

LAVRES JR., J.; MONTEIRO, F.A. Combinações de doses de nitrogênio e potássio para a produção e nutrição do capimmombaça. Boletim de Indústria Animal, v.59, n.2, p.102$114,2002$.

LAVRES JR., J.; MONTEIRO, F.A. Perfilhamento, área foliar e sistema radicular do capim-Mombaça submetido a combinações de doses de nitrogênio e potássio. Revista Brasileira de Zootecnia, v.32, n.5, p.1068-1075, 2003.

LEMAIRE, G.; CHAPMAN, D. Tissue flows in grazed plant communities. In: HODGSON, J.; ILLIUS, A.W. (Eds.). The ecology and management of grazing systems. 1.ed. Wallingford: CAB International, 1996. p.3-36.

MACEDO, M.C.M. Análise comparativa de recomendações de adubação em pastagem. In: PEDREIRA, C.G.S.; MOURA, J.C.; FARIA, V.P. (Eds.). Simpósio sobre manejo da pastagem. 21.ed. Piracicaba: Fundação de Estudos Agrários Luiz de Queiroz, 2004. p.317-355

MANARIN, C.A.; MONTEIRO, F.A. Nitrogênio na produção e diagnose foliar do capim-Mombaça. Boletim de Indústria Animal, v.59, n.2, p.115-123, 2002

MATTOS, W.T.; SANTOS, A.R.; ALMEIDA, A.A.S. et al. Aspectos produtivos e diagnose nutricional do capim-tanzânia submetido a doses de potássio. Magistra, v.14, n.1, p.37-44, 2002.

MITIDIERI, F.J. Respostas de cinco gramíneas forrageiras a níveis de calcário em um Latossolo Vermelho-Escuro. Piracicaba: Escola Superior de Agricultura "Luiz de Queiroz", 1995. 137p. Dissertação (Mestrado em Ciência Animal e Pastagem) Escola Superior de Agricultura "Luiz de Queiroz", 1995.

MONTEIRO, F.A.; WERNER, J.C. Efeitos das adubações nitrogenada e fosfatada em capim-Colonião em dois solos arenosos do Estado de São Paulo. Boletim de Indústria Animal, v.34, n.1, p.91-101, 1977.
RODRIGUES, R.C. Calcário, nitrogênio e enxofre para a recuperação do capim-Braquiária cultivado em solo proveniente de uma pastagem degradada. Piracicaba: Escola Superior de Agricultura "Luiz de Queiroz", 2002. 141p. Dissertação (Mestrado em Ciência Animal e Pastagem) - Escola Superior de Agricultura "Luiz de Queiroz", 2002.

SANTOS, J.H.S. Proporções de nitrato e amônio na nutrição e produção dos capins Aruana e Marandu. Piracicaba: Escola Superior de Agricultura "Luiz de Queiroz", 2003. 81p. Dissertação (Mestrado em Solos e Nutrição de Plantas) - Escola Superior de Agricultura "Luiz de Queiroz", 2003.

SANTOS JR., J.D.G.; MONTEIRO, F.A. Nutrição em nitrogênio do capim-marandu submetido a doses de nitrogênio e idades de crescimento. Boletim de Indústria Animal, v.60, n.2, p.139-146, 2003.

SANTOS JR., J.D.G. Fertilidade do solo no acúmulo de forragem e nutrição do capim-Tanzânia sob pastejo na região dos Cerrados. Piracicaba: Escola Superior de Agricultura "Luiz de Queiroz", 2005. 105p. Tese (Doutorado em Solos e Nutrição de Plantas) - Escola Superior de Agricultura "Luiz de Queiroz", 2005.

SARRUGE, J.R. Soluções nutritivas. Summa Phytopathologica, v.1, n.3, p.231-233, 1975 .

STATISTICAL ANALYSIS SYSTEM - SAS/STAT. User's guide, version 8.0. Cary: 2000. (CD-ROM).

WERNER, J.C. Adubação de pastagens. Nova Odessa: Instituto de Zootecnia, 1986. 49p. (Boletim Técnico, 18).

WERNER, J.C.; MONTEIRO, F.A.; CARRIEL, J.M. Efeitos da calagem em capim-colonião (Panicum maximum Jacq.) estabelecido. Boletim de Indústria Animal, v.36, n.2, p.247253, 1979.

WERNER, J.C.; PAULINO, V.T.; CANTARELLA, H. et al. Forrageiras. In: RAIJ, B. van; CANTARELLA, H.; QUAGGIO, J.A. et al. (Eds.). Recomendações de adubação e calagem para o Estado de São Paulo. Campinas: Instituto Agronômico, 1996. 285p. (Boletim Técnico, 100).
Recebido: 12/12/05 Aprovado: 13/09/06 